6. Sakaki H, Nishioka M, Kanda K, Takahashi Y. An investigation of the risk factors for infection with methicillin-resistant Staphylococcus aureus among patients in a neonatal intensive care unit. Am J Infect Control 2009;37:580-586.

7. Recommendations for prevention and control of methicillinresistant Staphylococcus aureus (MRSA) in medical and nursing facilities [in German]. Bundesgesundheitsblatt Gesundheitsforschung Gesundheitsschutz 2014;57:696-732.

8. Calfee DP, Salgado CD, Classen D, et al. Strategies to prevent transmission of methicillin-resistant Staphylococcus aureus in acute care hospitals. Infect Control Hosp Epidemiol 2008;29(Suppl 1):S62-S80.

9. Orendi JM, Coetzee N, Ellington MJ, et al. Community and nosocomial transmission of Panton-Valentine leucocidin-positive community-associated meticillin-resistant Staphylococcus aureus: implications for healthcare. J Hosp Infect 2010;75:258-264.

10. Kairet K, Ho E, Van Kerkhoven D, et al. USA300, A strain of community-associated methicillin-resistant Staphylococcus aureus, crossing Belgium's borders: outbreak of skin and soft tissue infections in a hospital in Belgium. Eur J Clin Microbiol Infect Dis 2017. doi: 10.1007/s10096-016-2883-6.

\section{Multiple Norovirus Outbreaks Due to Shredded, Dried, Laver Seaweed in Japan}

To the Editor-Seaweed has been an important traditional Japanese food, and various types of seaweed are widely used in soup stock, seasonings, and sushi dishes. The history of seaweed consumption is long and deeply rooted in Japanese tradition; remains of marine algae were even found in some prehistoric relics in the Japanese archipelago. Interestingly, comparative metagenome analyses of gut microbiota have suggested the presence of a unique microbiome derived from marine bacteria related to seaweed consumption in Japanese individuals. ${ }^{1}$ Among seaweeds, shredded, dried, laver seaweed is commonly used as a condiment; previously, it has rarely been considered to cause food poisoning. Here, we report unprecedented multiple norovirus outbreaks due to shredded, dried, laver seaweed packaged for long-term preservation in Japan.

Beginning on February 17, 2017, dozens of patients, mainly primary-school students, were treated in our clinic in Tachikawa City in Tokyo (Figure 1). A norovirus outbreak was responsible for illness in this unusually large cohort of patients. ${ }^{2,3}$ Ultimately, this outbreak included $\sim 1,100$ students and teachers from 7 primary schools in Tachikawa. All schools receive school lunches from the same centralized school lunch kitchen.

Although neither norovirus nor other pathogens were identified among cooking staff or in the kitchen facilities, the Tokyo metropolitan office identified the strain of norovirus that affected the outbreak patients in several packs of shredded, dried, laver seaweed used as condiments for the school lunches. ${ }^{2,3}$ The seaweed had been harvested in western Japan, Hyogo Prefecture. After being processed in a facility in Osaka

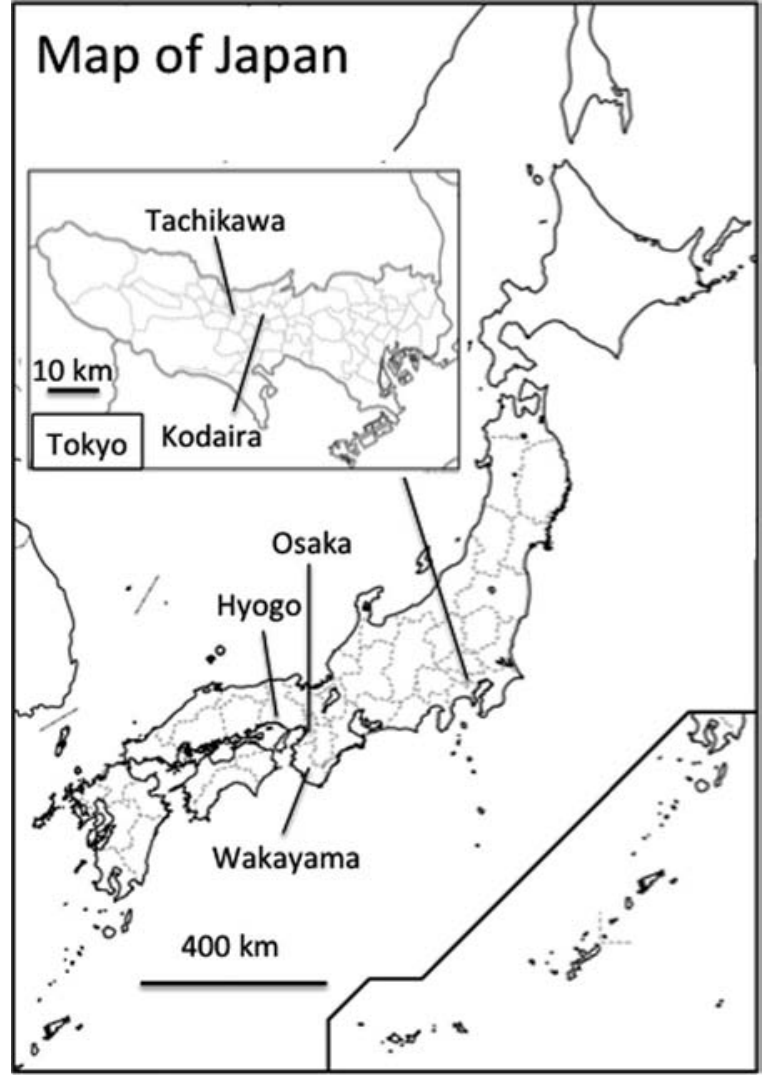

FIGURE 1. Geographical locations related to the multiple norovirus outbreaks due to shredded, dried, laver seaweed in Japan.

Prefecture, it was shipped nationwide with a December 2017 expiry date.

The company stated that the seaweed was heat treated using a conveyor-type machine for $\sim 7$ seconds at $240^{\circ} \mathrm{C}$ after boiling for 2 hours at $90^{\circ} \mathrm{C}$. An infected subcontractor had handled the seaweed with bare hands during the subsequent cutting and packaging process in the factory. In addition, 2 similar outbreaks had occurred in January 2017 involving $>800$ and $>100$ school children, respectively, in geographically distant cities, Wakayama Prefecture and Kodaira City in Tokyo. In both outbreaks, seaweed from the same company contaminated with the same norovirus strain was provided in the school lunches. ${ }^{4}$

Noroviruses are surprisingly resistant to harsh environmental conditions, and they are widely recognized as the leading cause of viral gastroenteritis due to foodborne infection across all age groups. ${ }^{5-7}$ The diagnosis of norovirus gastroenteritis cannot be made based on clinical features alone, and the widespread availability of molecular diagnostic tests has resulted in an increased awareness of norovirus-associated acute gastroenteritis worldwide. Because no vaccines or specific antiviral agents are currently available for the prevention or treatment of norovirus infection, rigorous hygiene (eg, hand washing) and heat treatment of foods and water remain the main prevention measures to combat norovirus 
transmission. However, prevention of norovirus infection is often challenging due to several factors: low infectious dose, prolonged survival on dry inanimate surfaces, resistance to commonly used disinfectants, long infectious period, and prolonged shedding. ${ }^{5-7}$

Common foods that can cause norovirus infection include oysters, shellfish, fruits, and vegetables, especially when they are consumed raw without heating. Recently, another norovirus outbreak associated with consumption of green seaweed that was eaten unheated with vinegar seasoning was reported in South Korean schools. ${ }^{8}$ However, outbreaks due to shredded, dried, laver seaweed processed for long-term preservation are unprecedented. As such, the current events provide several implications for preventing future norovirus outbreaks.

First, even in a packaged food product that has undergone heat-treatment, norovirus contamination can occur if it is handled by an infected person's bare hands during the manufacturing process. Although no regulations currently govern whether food manufacturers use gloves throughout the entire manufacturing process in Japan, more attention should be given to the risks of contamination. A previous report showed that the contaminated hands of food handlers could transfer infective norovirus even during gloving, ${ }^{9}$ so effective hand hygiene including handwashing with soap and water should be emphasized by food manufacturers.

In addition, the integrated and streamlined school-lunch provision system is highly vulnerable to norovirus outbreaks. An appropriate decentralized provision system should be explored, weighing the risks and costs prudently. In the modern society where highly connected distribution routes are well established, a single contaminated product can cause multiple outbreaks in geographically disparate places. The responsible local authorities should share infection information promptly and widely across geographic borders.

Finally, a comprehensive surveillance system including dried processed foods should be established to detect the source of such pathogens as early as possible to avoid further spread of the virus. Notably, an Italian study using a polymerase-chain reaction identification technique revealed the presence of norovirus in semidried tomatoes deemed "ready to eat." ${ }^{\text {"10 }}$ In the past, packaged dried foods may have been overlooked as the source of pathogens. In norovirus outbreaks, we should remember to consider this surprising source of infection.

\section{ACKNOW LEDGMENTS}

Financial support: No financial support was provided relevant to this article. Potential conflicts of interest: All authors report no conflicts of interest relevant to this article.
Kenzo Takahashi, MD, PhD; ${ }^{1,2}$ Masahiro Kami, $\mathrm{MD}, \mathrm{PhD}^{1,3}$

Affiliation: 1. Navitas Clinic, Tokyo, Japan; 2. Teikyo University Graduate School of Public Health, Tokyo, Japan; 3. Medical Governance Research Institute, Tokyo, Japan.

Address correspondence to Tetsuya Tanimoto, MD, Navitas Clinic, Shibasaki-cho 3-1-1, Tachikawa City, Tokyo, 190-0031, Japan (tetanimot@ yahoo.co.jp).

Infect Control Hosp Epidemiol 2017;38:885-887

(C) 2017 by The Society for Healthcare Epidemiology of America. All rights reserved. 0899-823X/2017/3807-0024. DOI: 10.1017/ice.2017.70

\section{REFERENCES}

1. Hehemann JH, Correc G, Barbeyron T, Helbert W, Czjzek M, Michel G. Transfer of carbohydrate-active enzymes from marine bacteria to Japanese gut microbiota. Nature 2010;464:908-912.

2. The second report on food poisoning due to school lunch in primary schools in Tachikawa city. Tokyo Metropolitan Government website. http://www.metro.tokyo.jp/tosei/hodohappyo/press/2017/02/28/11. html. [in Japanese] Published 2017. Accessed March 5, 2017.

3. Dried seaweed to blame for mass food poisoning at schools. Asahi Shimbun website. http://www.asahi.com/ajw/articles/ AJ201703010055.html. Published 2017. Accessed March 5, 2017.

4. On the occurrence of food poisoning. Tokyo Metropolitan Government website. http://www.metro.tokyo.jp/tosei/hodohappyo/press/2017/03/03/08.html. [in Japanese] Published 2017. Accessed March 5, 2017.

5. Li J, Predmore A, Divers E, Lou F. New interventions against human norovirus: progress, opportunities, and challenges. Annu Rev Food Sci Technol 2012;3:331-352.

6. DuPont HL. Acute infectious diarrhea in immunocompetent adults. N Engl J Med 2014;370:1532-1540.

7. Ahmed SM, Hall AJ, Robinson AE, et al. Global prevalence of norovirus in cases of gastroenteritis: a systematic review and meta-analysis. Lancet Infec Dis 2014;14:725-730.

8. Park JH, Jeong HS, Lee JS, et al. First norovirus outbreaks associated with consumption of green seaweed (Enteromorpha spp.) in South Korea. Epidemiol Infect 2015;143:515-521.

9. Roenqvist M, Aho E, Mikkelae A, et al. Norovirus transmission between hands, gloves, utensils, and fresh produce during simulated food handling. Appl Environ Microbiol 2014;80:5403-5410.

10. Serracca L, Rossini I, Battistini R, et al. Potential risk of norovirus infection due to the consumption of "ready to eat" food. Food Environ Virol 2012;4:89-92.

\section{Accidental Occupational Exposure to Burkholderia pseudomallei in South Korea Did Not Result in Melioidosis}

To the Editor-Melioidosis is caused by Burkholderia pseudomallei and presents a high mortality rate of up to $40 \% .{ }^{1} B$. pseudomallei is endemic in Southeast Asia and northern Australia. In Korea, there have been several imported cases; however, there have been no autochthonous cases. $^{2}$ 